\title{
Hemodiyaliz Hastalarında Progresif Gevşeme Egzersizinin Konfor Düzeyine Etkisi
}

\section{The Effect of Progressive Relaxation Exercise on Comfort Level in Hemodialysis Patients}

\author{
Gülay TURGAY ${ }^{1}$, Çiğdem ÖZDEMIR ELER ${ }^{2}$, Şeyda ÖKDEM ${ }^{1}$, Semiha KAYA ${ }^{3}$ \\ ${ }^{I}$ Dr. Öğr. Üyesi, Başkent Üniversitesi, Sağllk Hizmetleri Meslek Yüksekokulu. Ankara, Türkiye \\ ${ }^{2}$ Öğretim Görevlisi, Başkent Üniversitesi, Sağllk Hizmetleri Meslek Yüksekokulu. Ankara, Türkiye \\ ${ }^{3}$ Diyaliz Hemşiresi, Başkent Üniversitesi Hastanesi Diyaliz Merkezi. Ankara, Türkiye
}

* Bu çalışma 16-20 Ekim 2019 tarihleri arasında Antalya'da düzenlenen 29.Ulusal Nefroloji Hemşireliği Kongresi’nde sözlü bildiri olarak sunulmuş ve “Sözel Bildiri Birincilik Ödülü” almıştır.

Geliş Tarihi: 22 Ocak 2020

Kabul Tarihi: 30 Ocak 2020

İletişim / Correspondence:

Gülay TURGAY

E-posta: gturgay_gmh@hotmail.com

\section{Özet}

Amaç: Hemodiyaliz tedavisi alan hastalara uygulanan progresif gevşeme egzersizinin konfor düzeyine etkisini değerlendirmektir.

Gereç ve Yöntem: $\mathrm{Bu}$ araştırma, ön test-son test kontrol gruplu yarı deneysel olarak, 15 Nisan- 30 Mayıs 2019 tarihleri arasında bir diyaliz merkezinde, kontrol grubu 20 ve girişim grubu 20 hasta ile yapılmıştır. Araştırma verileri, "Hasta Tanıtım Formu" ve "Hemodiyaliz Konfor Ölçeği (HDKÖ)" kullanılarak toplanmıştır. Frekans dağılımı, ortalama, standart sapma ile veriler sunulmuş istatistiksel analizlerde, bağımsız gruplarda $t$ testi kullanılmıştır. Çalışmada anlamlılık düzeyi $\mathrm{p}<0.05$ olarak kabul edilmiştir.

Bulgular: Çalışmaya katılan girişim grubu hastaların \%50’si kadın, \%60` ${ }_{1} 40-59$ yaş aralığında; kontrol grubundaki hastaların \%50'si kadın, \%40‘1 40-59 yaş aralığındadır. Girişim grubundaki hastaların HDKÖ ortalama puanlarının ön testte $25,4 \pm 4,84$, son testte $27,6 \pm 3,96$ olduğu saptanmıştır. Kontrol grubundaki hastaların HDKÖ ortalama puanlarının ön testte $25,4 \pm 2,58$; son testte $24,25 \pm 2,67$ olduğu saptanmıştır.

Sonuç: Progresif gevşeme egzersizlerinin hemodiyaliz tedavisi alan hastaların konfor düzeyini arttırdığı saptanmıştır.

Anahtar sözcükler: Hemodiyaliz; Progresif Gevşeme Egzersizi; Konfor; Son Dönem Böbrek Yetmezliği; Hemşirelik.

\section{Abstract}

Objective: The aim of this study was to evaluate the effect of progressive relaxation exercise on comfort level of hemodialysis patients.

Material and Methods: This study was carried out with the control group 20 and experimental group 20 patients in a dialysis center between April 15 and May 30, 2019. The research data were collected using the "Patient Information Form" and "Hemodialysis Comfort Scale (HDSP)".Data were presented with frequency distribution, mean, standard deviation and $t$ test was used for independent groups. In the study, the significance level was accepted as $\mathrm{p}<0.05$. 
Results: Of the experimental group patients, $50 \%$ were female, $60 \%$ were in the $40-59$ age range, of the patients in the control group patients, $50 \%$ were female, , $40 \%$ were in the $40-59$ age range. The mean HDRS scores of the patients in the experimental group were $25.4 \pm 4.84$ in the pre-test and $27.6 \pm 3.96$ in the posttest. The mean HDRS scores of the patients in the control group were found to be $25.4 \pm 2.58$ in the pre-test and $24.25 \pm 2.67$ in the post-test.

Conclusion: Progressive relaxation exercises were found to increase the comfort level of patients receiving hemodialysis treatment.

Key words: Hemodialysis, Progressive Relaxation Exercise; Comfort; End Stage Renal Disease; Nursing.

\section{GíRIŞ}

Glomerüler Filtrasyon Hizında (GFH) azalma ile başlayan, vücudun sıvı-elektrolit ve metabolik işlevlerini sürdürmek için gerekli böbrek fonksiyonlarında kronik ve ilerleyici bozulma; Son Dönem Böbrek Yetmezliği (SDBY) olarak tanımlanmaktadır $(1,2)$. Türk Nefroloji Derneği 2018 yılı verilerine göre; SDBY'de en yaygın kullanılan renal replasman tedavi yöntemi \%74.8 oranında hemodiyalizdir. 2018 yılı hemodiyaliz tedavisi alan hasta sayısı 71.055 'tir (3).

Hemodiyaliz tedavisi alan bireyler, hastalık ve tedavi sürecine bağlı birçok semptomu yaşamakta ve beraberinde birçok sorunla baș etmek zorunda kalmaktadırlar (4,5). Ağrı, kaşıntı, yorgunluk, bulant1- kusma, kas krampları gibi semptomlar ve sık hastane yatışları, fiziksel disfonksiyon, beslenme değişiklikleri, sıvı kısıtlaması, ölüm korkusu ve uyku bozukluğu gibi değişiklikler hemodiyaliz tedavisi alan bireylerin konforunu ve yaşam kalitesini olumsuz yönde etkilemektedir $(4,6)$.

Temel insan gereksinimlerini karşılamanın o andaki deneyimi olarak ifade edilen konfor kavramı Kolcaba (1994) 'ya göre "bireyin gereksinimleri ile ilgili yardım, huzuru sağlama ve sorunların üstesinden gelebilme durumu olarak tanımlanmaktadır (7). Kolcaba (2003) konfor kuramında öncelikle bireyin var olan destek sistemleri ile karşılanamayan konfor gereksinimleri belirlenir. Belirlenen gereksinimleri karşılamak üzere girişimler planlanır, girişimlerin başarıya ulaşmasını etkileyen değişkenler dikkate alınarak değerlendirilir. Beklenen sonuç bireyin konforunun artmasidir (8).
Günümüzde kronik hastalı̆̆ 1 olan bireylerin konfor düzeylerini yükseltmek ve kaliteli bir yaşam sürdürmelerini sağlamak için gevşeme yöntemleri sıklıkla kullanılmaktadır. Progresif gevşeme egzersizleri (PGE) Dr. Jacopson tarafindan 1929 yılında geliştirilmiştir. PGE, insan vücudunda yüzden ayaklara kadar belli kas gruplarının kasılmasının ve gevşemesinin sağlandığı bir tür egzersizdir. Bu uygulamanın temel amac1, bireylerin kaslardaki gerginlik ile gevşeme arasındaki farkı hissedebilmeleri ve gerginlik durumunda kendi kendine gevşemeyi öğrenebilmeleridir. Yapılan çalıșmalarda PGE'nin kas gerginliğini, stresin etkilerini, anksiyeteyi, depresyonu, ağrıyı, yorgunluğu azaltmada, uykuya geçişi kolaylaştırmada, yaşam kalitesini iyileştirmede etkili olduğu saptanmıştır $(9,10)$.

Yapılan literatür incelemesinde, hemodiyaliz tedavisi alan bireylerde PGE'nin konfor düzeyine etkisini belirleyen çalışmaya rastlanılmamıştır. $\mathrm{Bu}$ nedenle bu araştırma, hemodiyaliz tedavisi alan bireylere uygulanan PGE'nin konfor düzeyine etkisini değerlendirmek amacıyla yapılmıştır.

\section{GEREÇ VE YÖNTEM}

\section{Araştırmanın Tipi}

Araştırma hemodiyaliz tedavisi alan bireylere uygulanan PGE'nin konfor düzeyine etkisini değerlendirmek amacı ile ön test-son test, kontrol gruplu, yarı deneysel olarak yapılmıştır.

\section{Araştırmanın Yeri ve Zamanı}

Araştırma, 15 Nisan- 30 Mayıs 2019 tarihleri arasında Ankara'daki bir üniversite hastanesinin diyaliz merkezinde yapılmıştır. 


\section{Araștırmanın Evreni ve Örneklemi}

Araştırmanın evrenini, veri toplama tarihleri arasında ilgili hastanenin diyaliz merkezlerinde tedavi alan tüm bireyler oluşturmuştur. Araştırmanın örneklemini, belirtilen merkezde iletişim kurulabilen, 18 yaş ve üstü, en az altı aydır hemodiyaliz tedavisi almakta olan ve araştırmaya katılmaya gönüllü bireyler oluşturmuştur. Eğitim süresince kontrol grubunun girişim grubundan etkilenmemesi için diyaliz merkezinde SalıPerşembe-Cumartesi günleri hemodiyaliz tedavisi alan bireyler girişim, Pazartesi-Çarşamba-Cuma günleri hemodiyaliz tedavisi alan bireyler kontrol (20) grubu olarak belirlenmiştir. Yapılan güç analizi sonucunda 0,20 etki büyüklüğü $\% 5$ hata payı ile çalışmanın gücü $\% \quad 80$ olarak saptanmıştır.

\section{Veri Toplama Araçları}

Araştırmanın verileri, "Hemodiyaliz Konfor Ölçeği (HDKÖ)" ve araştırmacı tarafından ilgili literatür (11-14) doğrultusunda hazırlanmış "Hasta Tanıtım Formu" kullanılarak toplanmıştır. Hasta Tanitım Formu, hastaların sosyodemografik ve hastalığa ilişkin özelliklerini içeren 11 sorudan oluşmaktadır. Hasta tanıtım formu; hastanın yaşı, cinsiyeti, medeni durumu, eğitim durumu, gelir durumu, sosyal güvencesi, mesleği, hemodiyaliz tedavisi aldığ yolu, haftalık diyaliz seans sayısı ve eşlik eden başka bir hastalığın varlığına ilişkin soruları içermektedir.

Hemodiyaliz Konfor Ölçeği (HDKÖ); ŞahinOrak ve arkadaşları tarafindan 2017 yılında geçerlik ve güvenirliği yapılan beşli likert tipinde bir ölçektir. Ölçek; dokuz maddeden ve iki alt boyuttan oluşmaktadır. Ölçeğin 4. maddesine verilen yanıtlardan "hiçbir zaman"1 puan, "çok nadir" 2 puan, "bazen" 3 puan, "çok sık" 4 puan ve "her zaman" 5 puan olarak puanlanmaktadır. Diğer maddelere (1-3,5-9) verilen yanttlardan "hiçbir zaman" 5 puan, "çok nadir" 4 puan, "bazen" 3 puan, "çok sık" 2 puan ve "her zaman" 1 puan olarak puanlanmaktadır. Ölçeğin iki alt boyutu bulunmaktadır. Bu alt boyutlar; "Rahatlama" (7-9. maddeler) ve "Üstesinden gelme" (16. maddeler)'dir. Rahatlama alt boyutundan en az 3.00 ve en çok 15.00 puan alınabilmekte; üstesinden gelme alt boyutundan ise en az 7.00 ve en çok 30.00 puan alınabilmektedir. HDKÖ'den alınacak en düşük puan 9, en yüksek puan $45^{\prime}$ tir. Alınan puan $45^{\prime}$ 'e yaklaştıkça konfor seviyesi yükselmektedir. Ölçeğin Cronbach's alfa güvenirlik katsayısı ise 0.87 'dir (11). Bu araştırmada da HDKÖ'nün cronbach alfa iç tutarlılık katsayısı 0,68 olarak saptanmıştır.

\section{Araştırmanın Uygulanması}

Araştırmanın ilk aşamasında, veri toplama formları; katılımcılara uygulama süreci hakkında bilgi verilip, araştırmaya katılmayı kabul eden bireylerden yazılı onam alındıktan sonra HD seansında araştırmacılar tarafindan uygulanmıştır. Araştırmanın ikinci aşamasında girişim grubundaki bireylere HD seansı başlamadan önce, eğitim odasında PGE hakkında eğitim verilmiştir. Eğitim ortalama 20 dakika sürmüştür. Eğitimde Türk Psikologlar Derneği Gevşeme Egzersizleri CD'si kullanılmıştır. PGE eğitimi aşamaları; gevşemenin tanımı, önemi, amac1, yararları ve dikkat edilmesi gereken durumların anlatılması, doğru nefes tekniklerinin öğretilmesi, egzersizin araştırmacı tarafından CD eşliğinde uygulayarak öğretimi ve soruların yanıtlanmasından oluşmaktadır. PGE araştırmacılar tarafindan hastalara birebir yaptırılmıştır. Girişim grubuna 4 hafta boyunca en az haftada iki kez PGE uygulanmıştır. Uygulama öncesinde uzman psikolog Yüksel Demirel'den PGE eğitimi alınmıştır. Kontrol grubundaki bireylere araştırma süresince herhangi bir girişim uygulanmamıştır. Araştırmanın son aşamasında hem girişim hem de kontrol grubuna HDKÖ, HD seansında araştırmacılar tarafından uygulanmıştır.

\section{Verilerin Değerlendirilmesi}

Araştırmadan elde edilen veriler bilgisayarda SPSS 22 programı kullanılarak analiz edilmiştir. Verilerin normallik kontrolüne Kolmogrow Smirnov testi ile bakılmış $(p>0,05)$ ve parametrik testler uygulanmıştır. Çalışmanın normal dağılım göstermesi, varyansların homojenliği ve grupların bağımsız olması durumunda örneklemin 30'dan büyük olma şartı aranmaksızın parametrik test kullanılabilmektedir (15). Frekans dağılımı, ortalama, standart sapma ile veriler sunulmuş istatistiksel analizlerde bağımsız gruplarda t testi kullanılmıştır. Araştırmada kullanılan ölçeğin iç tutarlığını değerlendirmek için Cronbach alfa 
katsayısı kullanılmıştır. Araştırmada istatistiksel anlamlılık düzeyi $\mathrm{p}<0.05$ olarak kabul edilmiştir.

\section{Araştırmanın Etik Yönü}

Araştırmanın uygunluğu ve yapılabilmesi için Başkent Üniversitesi Etik Kurulu'ndan etik onam (10/10/2018, KA18/289) ve araştırmanın yürütülebilmesi için çalışmanın yapıldığı üniversite hastanesinin başhekimliğinden kurum izni alın- mıştır. Araştırmada insan olgusunun kullanımında bireysel hakların korunması gerektiğinden “isteklilik, gönüllülük" ilkesi ışığında "Bilgilendirilmiş/Aydınlatılmış Onam" koşulu yerine getirilmiştir. Progresif Gevşeme Egzersiz CD'sinin kullanım izni Türk Psikologlar Derneği'nden, HDKÖ'nin kullanım izni Nuray Şahin Orak'tan mail yoluyla alınmıştır.

Tablo 1. Hemodiyaliz Tedavisi Alan Bireylerin Tanımlayııı Özelliklere Göre Dağılımı

\begin{tabular}{|c|c|c|c|c|c|}
\hline \multicolumn{2}{|l|}{ Sosyodemografik Özellikler } & \multicolumn{2}{|c|}{ Girişim Grubu } & \multicolumn{2}{|c|}{ Kontrol Grubu } \\
\hline & & $\mathbf{n}$ & $\%$ & $\mathbf{n}$ & $\%$ \\
\hline \multirow[t]{2}{*}{ Cinsiyet } & Kadın & 10 & 50 & 10 & 50 \\
\hline & Erkek & 10 & 50 & 10 & 50 \\
\hline \multirow[t]{3}{*}{ Yaş } & $20-39$ & 4 & 20 & 7 & 35 \\
\hline & $40-59$ & 12 & 60 & 8 & 40 \\
\hline & 60 ve üstü & 4 & 20 & 5 & 20 \\
\hline \multirow[t]{2}{*}{ Medeni Durum } & Evli & 13 & 65 & 17 & 85 \\
\hline & Bekar & 7 & 35 & 3 & 15 \\
\hline \multirow[t]{4}{*}{ Eğitim Durumu } & İlkokul & 5 & 25 & - & - \\
\hline & Ortaokul & 4 & 20 & 7 & 35 \\
\hline & Lise & 5 & 25 & 5 & 20 \\
\hline & Üniversite & 6 & 30 & 8 & 40 \\
\hline \multirow[t]{3}{*}{ Aylık Gelir Durumu } & Gelir Giderden Az & 5 & 25 & 6 & 30 \\
\hline & Gelir Gidere Denk & 14 & 70 & 14 & 70 \\
\hline & Gelir Giderden Fazla & 1 & 5 & - & - \\
\hline \multirow[t]{3}{*}{ Meslek } & Memur & 1 & 5 & 2 & 10 \\
\hline & Emekli & 11 & 55 & 14 & 70 \\
\hline & Ev Hanımı & 8 & 40 & 4 & 20 \\
\hline \multirow[t]{2}{*}{ Hemodiyaliz sıklığı } & Haftada 3 seans & 19 & 95 & 20 & 100 \\
\hline & Haftada 2 seans & 1 & 5 & - & - \\
\hline Vasküler Giriş Yolu & Arteriovenöz Fistül & 20 & 100 & 20 & 100 \\
\hline \multirow{3}{*}{$\begin{array}{l}\text { Hemodiyaliz Tedavisine Başlama } \\
\text { Zamanı }\end{array}$} & 6 ay- 5 y1l & 8 & 40 & 7 & 35 \\
\hline & $6-10$ y1l & 5 & 25 & 9 & 45 \\
\hline & 11 yıl ve üzeri & 7 & 35 & 4 & 20 \\
\hline \multirow[t]{2}{*}{ Sekonder Hastalık } & Evet & 14 & 70 & 7 & 35 \\
\hline & Hayır & 6 & 30 & 13 & 65 \\
\hline
\end{tabular}

Değerler yüzde olarak sunulmuştur 


\section{BULGULAR}

Girişim grubundaki bireylerin \%50'si kadın, \%60'1 40-59 yaş aralığında $(\overline{\mathrm{x}}=49,9 \pm 15,02$; min: 22-max:77), $\% 65$ 'i evli, \%30'u üniversite mezunu, \%55'i emekli ve \%70'inin aylık geliri giderine eşittir. Kontrol grubundaki bireylerin ise \%50'si kadın, \%40'ı 40-59 yaş aralığında $(\bar{x}=50,35 \pm 10,05$; min: 33-max:63), \%85'i evli, $\% 40$ '1 üniversite mezunu, $\% 70$ 'i emekli ve \%70'inin aylık geliri giderine eşittir (Tablo 1).

Hastalığa ilişkin özelliklere göre; girişim grubundaki bireylerin \%95'i, kontrol grubundaki bireylerin tamamı haftada üç seans hemodiyaliz tedavisi almaktadır. Vasküler giriş yolu, girişim ve kontrol grubundaki bireylerin tamamında arteriyovenöz fistüldür. Girişim grubundaki bireylerin \% 40'1 6ay- 5 y1l, kontrol grubundaki bireylerin \% 45'i 6-10 y1ldır hemodiyaliz tedavisi almaktadır. Girişim grubundaki bireylerin \% 70'inde, kontrol grubundaki bireylerin ise \% 35 'inde sekonder hastalık bulunmaktadır (Tablo $1)$.

Tablo 2'de girişim ve kontrol grubu hemodiyaliz tedavisi alan bireylerin HDKÖ ön test- son test puanlarının karşılaştırılması bulunmaktadır. Girişim grubundaki bireylerin HDKÖ ortalama puanlarının ön testte $25,4 \pm 4,84$ ve son testte $27,6 \pm 3,96$ olduğu saptanmıştır. Kontrol grubundaki bireylerin HDKÖ ortalama puanlarının ön testte $25,4 \pm 2,58$ ve son testte $24,25 \pm 2,67$ olduğu saptanmıştır. Girişim ve kontrol grubundaki bireylerin, gruplar arası HDKÖ puan ortalamaları arasinda fark anlamlı bulunmazken $(\mathrm{p}>0,05)$, grup içi HDKÖ puan ortalamaları arasındaki farkın istatistiksel olarak anlamlı olduğu saptanmıştır $(\mathrm{p}<0,05)$.

\section{TARTIŞMA}

Hemodiyaliz tedavisi alan bireylerde görülen semptomlar, bireyin konfor düzeyini ve yaşam kalitesini etkilemektedir (16). Son yllarda PGE kronik hastalığ 1 olan bireylerde semptom yönetiminin yanında bireyin konfor düzeyini arttırmak için de sıklıkla kullanılmaktadır (9).

Çalışmamızda, hemodiyaliz tedavisi alan bireylerin hemodiyaliz konfor ölçeği puanları karş1laştırıldığında, girişim ve kontrol grubundaki bireylerin, gruplar arası HDKÖ puan ortalamaları arasındaki fark anlamlı bulunmazken, grup içi HDKÖ puan ortalamaları arasındaki farkın istatistiksel olarak anlamlı olduğu saptanmıştır. PGE'nin hemodiyaliz tedavisi alan bireylerin konfor düzeyini olumlu yönde etkilediği saptanmıştır.

Literatür hemodiyaliz tedavisi alan bireylerin konfor düzeylerine ilişkin çalışmalara bakıld1ğında; Tabiee ve arkadaşlarının (2017) yaptıkları randomize kontrollü çalışmada sırt masajı ve hasta eğitiminin, hastaların konfor düzeyine etkisine bakılmış ve her iki gruptaki hastaların konfor düzeylerinin düşük olduğu tespit edilmiştir (6). Çalışkan'ın (2018) üremik hastalarda kaşıntının konfor düzeyine etkisini incelediği çalışmada, hemodiyaliz tedavisi alan hastaların hemodiyaliz tedavisi almayan hastalara göre yüksek konfora sahip olduğunu saptamıştır (12). Isnaini ve ark. (2018) arteriyovenöz fistül girişlerinde yapılan yavaş-derin nefes ve soğuk uygulamanın konfor düzeyine etkisini incelendiği çalışmada, girişim grubundaki bireylerin konfor düzeylerinin arttığ 1 saptanmıştır (17). Estridge ve ark. (2018) tarafindan sıv1 kısıtlaması ve konfor düzeyi arasındaki ilişkiyi belirlemek amacıyla yapılan tanımlayıcı kesitsel çalışmada, sıvı kısıtlaması ve konfor düzeyi arasındaki ilişkinin istatistiksel olarak anlamlı olmadığı saptanmıştır (18).

Tablo 2. Girişim ve Kontrol Grubu Hemodiyaliz Tedavisi Alan Bireylerin Hemodiyaliz Konfor Ölçeği (HDKÖ) Ön TestSon Test Puanlarının Karşılaştırılması

\begin{tabular}{|l|l|l|c|}
\hline \multirow{2}{*}{ HDKÖ } & Girişim & Kontrol & \multirow{2}{*}{$\mathbf{p}^{*}$} \\
\cline { 2 - 3 } & $\mathrm{X} \pm \mathrm{SS}$ & $\mathrm{X} \pm \mathrm{SS}$ & 0,149 \\
\hline Ön test & $25,4 \pm 4,84$ & $25,4 \pm 2,58$ & 0,160 \\
\hline Son test & $27,6 \pm 3,96$ & $24,25 \pm 2,67$ & \\
\hline $\mathbf{p}^{* *}$ & 0,039 & 0,032 & \\
\hline
\end{tabular}

Bağımsız gruplarda t-testi kullanılmıştır. 
Gevşeme egzersizlerinin hemodiyaliz tedavisi alan bireylerde; ağrı $(21)$, anksiyete $(19,20)$ ve yorgunluğu $(19,21)$ azalttı̆ğ; uyku $(19,23-25)$ ve yaşam kalitesini $(20,21,25)$ artırdı $\breve{g}_{1}$, öfke yönetimini (22) olumlu yönde etkilediğini gösteren çalışmalar bulunmaktadır. Ancak, literatürde hemodiyaliz tedavisi alan bireylere PGE uygulanıp konfor düzeyini inceleyen çalışmaya rastlanmamış ancak sınırlı sayıda diğer kronik hastalıklarda yapılan çalışmalara rastlanılmıştır. $\mathrm{Bu}$ çalışmalardan Yılmaz ve Arslan'ın (2015) meme kanserli bireylerle ön test-son test, kontrol gruplu, yarı deneysel olarak yaptıkları çalışmada bireylerin konfor düzeyi genel konfor ölçeği kullanılarak değerlendirilmiş ve PGE'nin konfor düzeyini olumlu etkilediği tespit edilmiştir (26).

Özcan'ın (2018) göğüs tüpü çıkarma işlemi öncesi uygulanan PGE, soğuk uygulama ve lokal anestezinin hastanın ağrı, konfor düzeyi ve yaşam bulguları üzerine etkisini incelediği çalışmada, hastaların konfor düzeyleri konfor skalası ile değerlendirilmiş ve konfor düzeyinin PGE grubunda artış gösterdiği, kontrol grubunda ise işlem öncesi ile hemen hemen aynı olduğu saptanmıştır (27).

\section{SONUÇ}

Sonuç olarak, bu çalışmada PGE'nin hemodiyaliz tedavisi alan bireylerin konfor düzeyini arttırdığ görülmektedir. Hemodiyaliz tedavisi alan bireylere PGE'nin öğretilmesi ve periyodik olarak uygulanmasının sağlanması, diyaliz ünitelerinde çalışan hemşirelerin PGE'nin uygulaması hakkında bilgi sahibi olmaları ve hasta bakım sürecine dahil edilmesi konusunda desteklenmesi önerilmektedir. Ayrıca bu alanda yapılan çalışmaların sınırlı sayıda olması nedeniyle örneklem sayısı yüksek izlem çalışmaları ile randomize kontrollü deneysel çalışmalara gereksinim olduğu düşünülmektedir.

\section{KAYNAKLAR}

1. Port MC. Patofizyolojinin Temelleri. Çeviren: Tanrı̈̈ver M, Sarı A. 4. Basım. Palme Yayıncılık, Ankara; 2018.

2. Garcia GG, Jha V. Chronic Kidney Disease in Disaduentaged Populations. Hong Kong Journal of Nephrology 2015;17:1-5.

3. Türk Nefroloji Derneği Registry 2018. Türkiye'de Nefroloji, Diyaliz ve Transplantasyon.

4. Akça KN, Doğan A. Hemodiyaliz Hastalarının Diyaliz Sonrası Yaşadığı Sorunlar ve Evde Bakım Gereksinimleri. Bozok Tip Dergisi 2011;1:15-22.

5. Karadağ E, Kılıç SP, Karatay G, Metin Ö. Effect of Baby Oil on Pruritus, Sleep Quality and Quality of Life in Hemodialysis Patients: Preteset-Post Test Model With Control Groups. Japan Journal of Nursing Science 2014; 11: 180-189.

6. Tabiee S, Momeni A, Alireza S. The Effects of Comfort-Based Interventions (Back Massage and Patient and Family Education) on The Level of Comfort Among Hemodialysis Patients. Mod Care J 2017;14(3):64-87.

7. Çınar YŞ. Kolcaba’nın Konfor Kuramı. Ege Üniversitesi Hemşirelik Yüksek Okulu Dergisi 2011;27 (2) : 79-88.

8. Karabacak Ü, Acaroğlu R. Konfor kuramı. Maltepe Üniversitesi Bilim Ve Sanat Dergisi 2011; 4(1):197-202.

9. Kapucu S, Kütmeç, YC. Kronik Hastalıklarda Progresif Gevşeme Egzersizlerinin Yararı. F.Ü.Sağ.Bil.Tıp.Derg 2018;32 (2): 111-114.

10. Türk Psikologlar Derneği Yayınları. Stresle Etkili Başa Çıkma Yöntemi. “Gevşeme Egzersizleri CD”. 2014, Ankara.

11. Şahin Orak N, Çınar Pakyüz S, Kartal A. Ölçek Geliştirme Çalışması. Türk Nefroloji, Diyaliz ve Transplantasyon Hemşireleri Derneği Nefroloji Hemşireliği Dergisi 2017; 12(2):68-77.

12. Çalışkan T, Çınar Pakyüz S. Hemodiyaliz Tedavisi Alan ve Almayan Üremik Hastalarda Kaşıntı Konforu Etkiler mi?. Türk Nefroloji, Diyaliz ve Transplantasyon Hemşireleri Derneği Nefroloji Hemşireliği Dergisi 2019;14 (3): 84-96. 
13. Turgay G, Tutal E, Sezer S. Hemodiyaliz Hastalarının Günlük Yaşam Aktiviteleri, Yeti Yitimi, Depresyon ve Komorbidite Yönünden Değerlendirilmesi. Türk Nefroloji Diyaliz ve Transplantasyon Dergisi 2017;26(3):311-316.

14. Turgay G, Tutal E, Sezer S. Restless Legs Syndrome, Sleep Quality and Fatigue in Hemodialysis Patients. Türk Nefroloji Diyaliz ve Transplantasyon Dergisi 2018; 2(2):196-203.

15. Kim TK. T Test As a Parametric Statistic. Korean Journal of Anesthesiology 2015; 68(6); 540-6.

16. Süleymanlar G, Utaş C, Arinsoy T, Ateş K, Altun BA. Population-Basedsurvey of Chronic Renal Disease in Turkey the CREDIT Study. Nephrology Dialysis Transplantation 2011;26(6): 1862-1871.

17. Isnaini N, Hidayati T, Sumaryani S. Effect of Combination of Slow Deep Breathing and Ice Therapy towards Comfort Level in Arteriovenous Fistula Insertion of Hemodialysis Patients in PKU Muhammadiyah Hospital Yogyakarta Nur. Indonesian Journal of Clinical Pharmacy 2018;7 (1);45-51.

18. Estridge KM, Morris DL, Kolcaba K, Winkelman, C. Comfort and Fluid Retention in Adult Patients Receiving Hemodialysis. Nephrology Nursing Journal 2018;45(1): 25-33.

19. Amini E, Goudarzi I, Masoudi R, Ahmadi A, Momeni A. Effect of Progressive Muscle Relaxation and Aerobic Exercise on Anxiety, Sleep Quality, And Fatigue in Patients With Chronic Renal Failure Undergoing Hemodialysis. International Journal of Pharmaceutical and Clinical Research 2016;8(12); 1634-1639.

20. Kuzeyli Y, Fadıloğlu Ç. Diyaliz Hastalarında Progresif Gevşeme Yöntemlerinin Kaygı Düzeyi ve Yaşam Kalitesine Olan Etkisinin İncelenmesi. Ege Üniversitesi Hemşirelik Yüksek Okulu Dergisi 2005; 21(1);33-45.

21. Kaplan E. 2012. Diyaliz Hastalarında Progresif Gevşeme Egzersizlerinin Ağrı, Yorgunluk ve Yaşam Kalitesi Üzerine Etkisi. Yayınlanmamış Yüksek Lisans Tezi, Gaziantep Üniversitesi Să̆lık Bilimleri Enstitüsü, Gaziantep.

22. Demir B, Okanlı A. Hemodiyaliz Hastalarında Gevşeme Egzersizi ve Öfke Eğitiminin Öfke İfadelerine Etkisi. Anadolu Hemşirelik ve Sağlık Bilimleri Dergisi 2013;16 (4):227-33.

23. Saeedi M, Ashktorab T, Saatchi K, Zayeri F, Akbari AAS. The Effect of Progressive Muscle Relaxation on Sleep Quality of Patients Undergoing Haemodialysis. Journal Critical Care Nurse 2012; 5(1): 23-29.

24. Saeedi M, Saatchi K, Zayeri F, Akbari AAS, Askhtorab T. The Effect of Progressive Muscle Relaxation on Sleep Quality of Patients Undergoing Hemodialysis. Critical Care Nurse Journal 2006;5(1): 7044.

25. Erdem N. 2005. Diyaliz Hastalarında Progresif Gevşeme Egzersizlerinin Uyku ve Yaşam Kalitesine Etkisinin İncelenmesi. Yayınlanmamış Doktora Tezi, Atatürk Üniversitesi Sağlık Bilimleri Enstitüsü, Erzurum.

26. Yilmaz GS, Arslan S. Effects of Progressive Relaxation Exercises on Anxiety and Comfort of Turkish Breast Cancer Patients Receiving Chemotherapy. Asian Pac J Cancer Prev 2015;16 (1): 217-22.

27. Özcan, N. 2018. Göğüs Tüpü Çıkarma İşlemi Öncesi Uygulanan Progresif Kas Gevşeme Egzersizi, Soğuk Uygulama Ve Lokal Anestezinin Hastanın Ağrı, Konfor Düzeyi Ve Yaşam Bulguları Üzerine Etkisi, Yayınlanmamış Yüksek Lisans Tezi, Cumhuriyet Üniversitesi Sağlık Bilimleri Enstitüsü, Sivas. 